\title{
Ego-Dystonic Zoophilia: A case report with treatment plan and a critical look at the current state
}

\author{
Sangeeta Singg* \\ Angelo State University, USA
}

\begin{abstract}
Sexual contact with animals referred to as zoophilia or bestiality has interested diverse scholars over six decades, yet its etiology and treatment still remain unclear. The purpose of the present case report was to reconcile some of the conflicting past and recent information on zoophilia, provide information about etiology and treatment of zoophilia, and pose some pertinent questions for future research. A case of a 24-year-old man, Paul (pseudonym) who had been having sexual contact with cows since he was 15 was presented. His behavior became ego-dystonic and he sought help from his priest. After the confession, the priest referred him for psychotherapy. Multimodal therapy and self-directed spiritual counseling (at Paul's request) were used to address the multiple issues. The treatment resulted in satisfactory outcomes. Paul stopped having sex with cows, began dating, and got married. During all follow-up sessions, Paul denied any relapse when he visited his family farm on special occasions. Contrary to some recent studies, this case study supported the earlier research conclusions and presented new hypotheses. For the first time to the author's knowledge, a comprehensive treatment plan which resulted in successful outcomes was presented.
\end{abstract}

\section{Introduction}

Sexual contact with animals (SCA), clinically referred to as zoophilia and legally as bestiality, has interested diverse scholars over six decades, yet its etiology and treatment still remain unclear. A taboo subject in our civilized society, this phenomenon has been in existence among many cultures since the prehistoric times [1]. Even though sex with animals in 31 United States and many other countries is considered animal abuse and also a crime against nature [2,3], the prevalence rates are noteworthy. They range from $8.3 \%$ [4] to $4.9 \%$ [5] for men and 3.6\% [6] to $1.9 \%$ [4] for women in normal population. The estimates of prevalence differ among studies because it is difficult to conduct sexual research and obtain random samples [7]. In 1970s the farming population declined in U.S. causing a lack of opportunity to live with animals which is considered the main reason for the change in rates over times [8]. Interestingly, zoophilia has been reported to be much higher in psychiatric inpatients (55\%) as compared to medical inpatients (10\%) and psychiatric staff (15\%). It was suggested that the questions about SCA or fantasies of such acts should be routinely included in the psychiatric clinical interviews [9]. There is a lack of current information about the prevalence of zoophilia in the different parts of the world. This is mainly because of the taboo nature of the subject and legal implications in many jurisdictions [10].

Conflicting results have been reported by the studies of zoophilia which are few in number. These studies include case studies and surveys with clinical and nonclinical participants. There are two groups of researchers with differing views about this taboo phenomenon of SCA. One group of researchers [e.g., 4,5,11] report zoophilia to be mostly ego-dystonic and stemming from a dysfunctional background. I call this view as the "traditional view of zoophilia." Another group of more recent researchers [e.g., 1,8,12,13] report that not all persons with zoophilia come from dysfunctional backgrounds or experience distress due to their experience of having SCA. They contend that in fact these individuals prefer SCA or may even have this form of sexual orientation. I call this view as the "modern view of zoophilia." It is important to identify if the person's zoophilia is ego-dystonic or egosyntonic because of the treatment implications. When one's behaviors/ thoughts/feelings are in conflict with one's "ideal self-image," they are considered ego-dystonic and when they are in harmony with the "ideal self-image," they are referred to as ego-syntonic [14].

In the fifth edition of Diagnostic and Statistical Manual (DSM5), Zoophilia is categorized under "Other Specified Paraphilic Disorder" referring to "recurrent and intense sexual arousal involving ... animals" and causing "marked distress and impairment in social, occupational and other important areas of functioning" [15, p. 705] Further, zoophilia is considered abnormal if this behavior becomes ego-dystonic and harmful to oneself or others. It can also be a crime if the law of the land considers it so in which case the person faces certain legal repercussions. Often times the behavior of sexual contact with the animal(s) takes place in one's home or on the farm/stable which prevents public viewing or reporting. Most commonly preferred animals for sex have been reported to be dogs and horses $[1,8]$. The purpose of presenting the present case report is to reconcile some of the conflicting past and recent information on zoophilia, provide additional information about its etiology and treatment, and pose some pertinent questions for future research.

\section{Case presentation}

A zoophilia case of a 24-year-old Caucasian man, Paul (pseudonym) and his treatment program that led to a satisfactory treatment outcome

Correspondence to: Sangeeta Singg, Angelo State University, San Angelo, Texas 76909, USA, Tel: 1-325-223-8606; Fax: 1-325-942-2290; E-mail: sangeeta.singg@ angelo.edu

Key words: zoophilia, bestiality, paraphilia, zoosexuality, zooerasty, animal abuse, sex with animals, sexual contact with animals

Received: January 03, 2017; Accepted: January 17, 2017; Published: January 19, 2017 
is presented after obtaining his signed Post-Treatment Informed Consent for publishing this case report. The consent form stated that Paul's real name, residence, schools, and work places would be kept confidential to protect his identity; thus, all identifying data about Paul has been changed for this report to protect his identity. He was referred for psychotherapy by his priest, Fr. John (pseudonym) after his confession of sexual contact with cows at his father's farm. During the initial interview, he identified this to be his major issue since he was 15 years old and stated that he had "made a mess of his life." $\mathrm{He}$ said he was afraid to see me, but Fr. John "insisted that I see you." He admitted being very uncomfortable talking about this and stated that he "definitely could not talk about all this to a man." I reassured him about the confidentiality, about my role in helping people finding answers to their issues, and the collaborative nature of the process. I invited him to help me fully understand the antecedents of his behavior and its impact on his life. I also thanked him for trusting me. My display of respect and reassurance seemed to reduce his embarrassment. I explained to Paul that best thing going for him at the time was his discomfort and decision to change even though the change would require hard work, discipline, and a real commitment on his part. Paul said he was willing to make changes because he was "sick of feeling bad."

He indicated that his sexual behavior was impacting several areas of his life and making it very "difficult to continue." He denied suicidal ideation at the time he came to see me, but admitted having it before he went for confession with Fr. John. I gave him the Multimodal LifeHistory Questionnaire (MLHQ) to complete because sexual disorders are often part of a wider range of dysfunction requiring multimodal approach [16]. Multimodal therapy by Lazarus seeks to understand and intervene at seven levels of human functioning: behavior, affect, sensation, imagery, cognition, interpersonal relations, and drugs and biological factors (BASIC I.D.). Because Paul's case also involved the spiritual dimension, multimodal orientation is the best approach to incorporate this aspect. "Faith" or "Spiritual" components are part of the cognitive and affective aspects [16] of human functioning and can be addressed very well within the multimodal therapeutic plan. Thus multimodal therapy and psychospiritual counseling (at Paul's request) were used to address the multiple issues presented by Paul. It took two sessions to go over the multiple issues related to his presenting problem and background after he completed the MLHQ. The following relevant information was revealed from the questionnaire and the clinical interview.

A 17 years old cousin visiting from another state introduced Paul to having sexual contact with cows. The cousin told him that he preferred this to masturbation. Paul continued this behavior on a weekly basis or more for about 9 years. In addition to farming, his father raised and sold beef cows regularly, thus, there were several cows that Paul "used" for this purpose. Paul said, "Since I moved to the city two months back, I have not physically done it, but had a few dreams about it." He did not report feeling emotionally attached with any of the cows.

The youngest of three children of Catholic parents, Paul stated that his parents did not want another child when he was born. Paul was 11 and 13 years younger than his two brothers. He described his parents as hardworking and busy who did not have much time for him. Being a loner he rarely did things with his friends from school, partly because he lived on a large farm far away from other schoolmates. He did not have any close friends. His father and two older brothers liked hunting, but they did not like taking Paul with them because he was too young. He said he often felt rejected when he was left with mother at home. Later when he became older he was allowed to go hunting with them, but he felt bad seeing the animals being killed. Thus, he stopped accompanying them for this activity for which they often called him "sissy."

Paul said he was not very close to his father and brothers, but he felt closer to his mother and helped her with cooking and cleaning. However, he couldn't recall either of his parents ever telling him that they loved him or being supportive when he felt bad or alone. He spent a lot of time alone watching TV and fantasizing about being an actor and a singer. Paul denied any childhood sexual abuse, but felt that he was emotionally abused by his brothers and father. He said his parents and brothers often teased him about his singing.

Paul did "okay" in high school and at age 23, he completed his Bachelor's degree and began working in a local business. After 10 months he left his small rural community and moved to a city to work for a large retail store. On exploring further, Paul reported being shy and did not date girls in high school, but dated two girls in college. He kissed them but did not have sexual intercourse with them because he was afraid of intimacy. He reported that he really liked the last girl he dated but could not bring himself to have sex with her because of his feelings of self-inadequacy and fear about "giving her some disease." I commended him for acting responsible in this respect. His fear was that he might have some "strange disease" because he read about the diseases one can acquire from animals. He felt that God might punish him with some disease for his sins as He did the "Egyptians" (in the Bible). He often referred to God and Bible while talking about his SCA problems. He said he attended church with his family, but felt "like a hypocrite," especially after partaking of the Eucharist; he had to do this because his family and other people were watching. Even though, Fr. John was mainly working with Paul regarding his spiritual issues, he was allowed to talk freely about them in his sessions with me as well because his behavior, affect, and spirituality were strongly intertwined. Fr. John used Alcoholics Anonymous 12 Step Program principles [17] with Paul. The Alcoholics Anonymous 12 steps program is a standard for recovery from nearly any kind of addiction. Surrendering to the higher power is one of the major parts of this program, which was highly stressed by Fr. John while working with Paul.

Paul seemed to know a lot about zoophilia and bestiality. When I asked him how he knew all this, he said he had read up on it and tried to help himself several times. I commended him for his insights and desire to change. I advised him that I did not have any magic bullet for fixing his problem, and that the power to change was within himself. I also told him that several factors were in his favor. The fact that he was so miserable about his situation, had insights into his behavior, and was motivated to change were indicators of a good prognosis if he would invest his time and energy in exploring and changing his situation. I suggested that he should follow a self-directed spiritual program with Fr. John and it will remain an important part of his therapeutic plan. Leaving the farm, moving to the city, and stopping all work which involved cows or any other animals were considered important basic steps of the treatment. Paul felt that he still needed to forgive himself and feel okay as a man and had strong feelings of guilt and shame about "abusing the innocent creatures of God who had no say." He stated, "I can't live with myself anymore" and "if Bible is correct, then I can be saved and transformed." Now and then his eyes would become teary while talking about various events and difficult feelings. When persons begin experiencing "marked distress and impairment in social, occupational and other important areas of functioning," [15] then they feel motivated to seek treatment. Such egodystonic (causing mental pain) cases have a better prognosis than those 
who do not feel significantly disturbing feelings about their behavior or are ego syntonic [14]. Ego-dystonic zoophilia is accompanied with great mental anguish, shame, anxiety, hopelessness and depression, all symptoms experienced by Paul.

\section{Therapeutic process}

I observed Paul to be an intelligent, likeable, and sensitive young man who had made some self-defeating choices facilitated by loneliness, boredom, feelings of rejection, and some situational factors. Of the many issues presented by Paul, I narrowed them down to select key issues assessed with respect to the BASIC I.D. of Multimodal Therapy [16]. Paul's Multimodal Profile is presented in Table 1.

Paul's behavior, affect, and cognition were identified involving the most troubling symptoms and were considered the major areas of focus in Paul's treatment. Before beginning the treatment program for the major problem areas, some other measures were taken regarding his other issues. For example, Paul reported that drinking a glass of wine reduced his anxiety and helped him to sleep better. After educating Paul on use of alcohol for self-medication, diet, and sleep hygiene, I taught him some quick techniques of relaxation and gave a relaxation tape to be used at home. He liked the guided imagery and breathing exercises as healthier alternatives. Because of his fear of zoonoses, a referral to an urologist was made in a different city for a complete check-up. The diseases that can be transmitted from animals to humans are called zoonoses. Of over 200 identified zoonoses, information about 39 most prevalent zoonoses is available at the Washington State Department of Health website [18]. Three most dangerous ones are Leptospirosis (leading to meningitis), Echinococcosis (causing cysts to grow in the liver, brain, lungs, and other organs), and Rabies [19]. SCA is also a risk factor for penile cancer. In a study of 118 penile cancer patients, $44.9 \%$ patients had reported SCA [20]. I was not aware of all of these diseases and reading what Paul prompted me to read was an eye opener. After six weeks into therapy, Paul received a clean bill of health from his doctor regarding the zoonoses. He felt relieved and his doctor advised him not to resume SCA.

With the basic interventions in place, I began working with Paul's modality profile by implementing the techniques listed in Table 1 . The reason for each technique was explained to Paul to his satisfaction. He was reminded several times that the therapeutic process was collaborative and the power lied with him for the success of therapy. $\mathrm{He}$ was reinforced with praise at every step toward his goals. The therapy continued for 32 weekly sessions and 12 follow-up sessions. Paul liked his job and felt his superiors liked him. This became a big plus for Paul's treatment. This built his self-esteem and sense of independence plus the contact with his co-workers served to further bolster his mood.

The main treatment goals for any paraphilia are extinguishing the maladaptive behavior and preventing the relapse. The first goal was achieved by Paul himself leaving the farm and forsaking any opportunity to be around cows. His new environment included his new church, apartment complex, and work place. The rest of the therapeutic interventions were geared toward learning and practicing the new behaviors to replace the maladaptive ones and preventing a relapse. I used the techniques listed in Table 1 to deal with different issues under the seven modalities. The drugs/biological issue was resolved with the urologist's report which also alleviated to some extent the fear of getting intimate with a woman and that God was punishing Paul with some bad disease. The aversive imagery was beneficial for changing the behaviors and the content of the dreams. Directing Paul's sexual energy toward women and using this as a substitute for the SCA required multiple maneuvers at the same time. For example, while working at the behavior modality, cognition and imagery were also worked at the same time.

Because Lazarus considered it "necessary" for people to imagine

Table 1. Multimodal Profile of Paul.

\begin{tabular}{|c|c|}
\hline Modality/Problem & Treatment \\
\hline \multicolumn{2}{|l|}{ Behavior } \\
\hline Habitual Sexual contact with cows & Aversive imagery, Stimulus control, Abstinence and substitution \\
\hline Avoidance of intimacy with women & Relational therapy, Disputation of irrational ideas, Paradoxical intention \\
\hline Trouble falling asleep & Relaxation and Prayer (Paul's suggestion) \\
\hline \multicolumn{2}{|l|}{ Affect } \\
\hline Anxiety attacks & Anxiety-management training, Guided imagery \\
\hline Depressed mood & Feeling identification, Ellis' A-B-C-D-E paradigm \\
\hline Guilt, shame with spiritual overtones & Self-instruction training, Total surrender to God \& prayer (Paul's suggestion/work with Fr. John) \\
\hline Feelings of isolation & Social activities supported by Paul's work, Volunteering/helping the disadvantaged \\
\hline \multicolumn{2}{|l|}{ Sensation } \\
\hline Having a disease & Disputation of irrational ideas, medical check-up \\
\hline \multicolumn{2}{|l|}{ Imagery } \\
\hline Dreams of having sex with cows or becoming a cow & Gestalt dream work; Empty chair \\
\hline Being ridiculed/teased by brothers and father & Desensitization, Time projection (forward) \\
\hline \multicolumn{2}{|l|}{ Cognition } \\
\hline $\begin{array}{l}\text { Repeating thoughts: } \\
\text { "I must be demon possessed," } \\
\text { "Why do I continue even though } \\
\text { I know it is wrong?" } \\
\text { "I have sinned against God." }\end{array}$ & $\begin{array}{l}\text { Disputation of irrational ideas } \\
\text { Thought stopping, Reframing, } \\
\text { spiritual dialog sessions with Fr. John }\end{array}$ \\
\hline \multicolumn{2}{|l|}{ Interpersonal Relationships } \\
\hline Discomfort around father/brothers & Assertiveness training, Reframing, Empty-chair \\
\hline Distance from God and fellowmen & Joining the young singles' group in church, Spiritual therapy with Fr. John \\
\hline No friends & Friendship training \\
\hline \multicolumn{2}{|l|}{ Drugs/Biologica 1} \\
\hline Physical health concerns & Referral to an M.D. for full check up \\
\hline
\end{tabular}


what they want before they can actually achieve it [16], one of the things I had Paul do regularly was to imagine seeing himself with a beautiful lady eating, singing, hugging, kissing, and doing any other activities he enjoyed. I instructed him to leave off the sexual intercourse from the imagery. I did this for two purposes: (1) for him to stay true to his Catholic values; and (2) to use this instruction as a paradoxical intention. Paradoxical intention is somewhat like reverse psychology. In Paul's case, I felt either of the two outcomes was going to be helpful. If Paul did not have sexual intercourse with the lady in the imagery, it would protect him from feeling guilty due to violation of his Catholic values. However, if he did opposite and have sexual intercourse in the imagery, it would encourage and provide a future avenue to having sex with a woman. Paul experienced both options with this exercise. I also had him describe a day from the time he wakes up to the time he goes to sleep five years in the future. This exercise clarified his values and future goals, which helped Paul progressing with his goals even after the therapy was terminated.

A lot of time was spent on friendship training, disputation of irrational ideas, empty chair, Gestalt dream work, assertiveness training, reframing, and using A-B-C-D-E paradigm. Sometimes, Paul would relate what he talked with Fr. John and how it applied to his current issues. Our work together remained client-entered with active listening and reflection of feelings even when cognitive or behavioral techniques were used. After the dream work and the aversive imagery, Paul reported that his dreams about cows had become infrequent. After 23 sessions and completion of friendship training, disputation of irrational ideas, dream work, and guided imagery, Paul indicated that he was ready to put in practice what he had learned. He met a young lady in his singles' group who seemed to like him and he wanted to ask her for a date. Both Fr. John and I agreed that this was a good idea; however, I suggested that Paul should move slowly into this relationship. The young lady and Paul began doing a lot of fun things including going to the movies, attending church functions together, shopping, eating out, and swimming in the local lake. Paul reported kissing her and feeling a strong attraction to her. But both of them decided not to have sexual intercourse because of their Catholic belief system. Fr. John and Paul also worked a lot on understanding who Paul was in Christ and forgiveness of his sins. He felt that Eucharist after he had confessed his mortal sin of SCA was healing, restoring and cleansing of his mind, body and soul. His work with Fr. John had powerful and changing impact on his belief that he had sinned against God and that God would punish him. He began talking more about "Good God" and himself as the "forgiven." Also, he forgave his brothers, parents, and himself for violating the "innocent creatures of God." A lot of reframing and empty chair work went into effecting this outcome.

After 30 sessions, I felt it was time to test the strength of aversive conditioning about SCA and new insights into his relationships with his father and brothers. Thus, I asked him to go for one night visit to his father's home. I asked him to invite his girlfriend to go with him. He reported that all went well and he did not feel the need or urge to have sexual contact with cows. In fact, he reported feeling nauseated with the smell of the pasture and week in his legs if he went closer to the area where the cows were grazing. He also had developed aversion to beef which was an unintended side effect of the aversive imagery. $\mathrm{He}$ also said that he felt more at ease with his parents and brother. His father reacted to his new demeanor positively. I asked him to repeat the visit for two nights for upcoming Thanksgiving holiday. He reported that his girlfriend could not accompany him but he invited a foreign student instead who lived in his apartment complex to go home with him for Thanksgiving. He said he remained busy with his friend and the family and helping his mother in the kitchen. The SCA issues did not emerge.

After a couple more sessions I told Paul that it was time to end the weekly therapy sessions. Paul felt a bit apprehensive about not seeing me every week, but felt better after we decided to meet for the follow-up sessions to check on his continued progress. In order to assess if the gains made by Paul continued over five years, 12 follow-up sessions were scheduled: 2 sessions after two weeks interval, 4 every month, 3 every three months and 1 every year for three years. I gave Paul permission to call me anytime he felt an issue had resurfaced or he needed to discuss anything before our follow-up sessions. Fr. John remained actively involved in providing the spiritual support to Paul as needed until Fr. John moved to another town. But he continued keeping in touch with Paul via phone. Paul began going for confession as needed to the priest in his new church in the city. He said he had not needed to confess about any additional sins involving SCA.

During the follow-up session-10, Paul discussed his decision to get married to his girlfriend. Both of them met with their priest for pre- and post-marital spiritual counseling. They had decided early on to postpone having a sexual intercourse until after their wedding. However, at different times, Paul reported masturbating with various fantasies of being with his girlfriend after which he had to go for confessions with Fr. John. Both Fr. John and I agreed that at least these experiences were not with the fantasy of being with the cows. Nevertheless, abstinence remained a strong goal behaviorally and spiritually for Paul until he got married at the age of 27. Not being a Catholic myself, empathizing with Paul was a challenge at times.

\section{Treatment outcome}

Paul reported tangible gains by separating from the SCA: sleeping better and feeling more rested, feeling more relaxed and enjoying his work, not having to deal with the spiritual guilt and fear of having a disease due to his sexual behavior and sinning against God, feeling more confident and hopeful toward his future, feeling gratification from volunteer and social activities, having clear future goals and feeling more aware of his values and feelings, achieving a goal of female closeness and sex within the marriage, and feelings of accomplishment and increased self-esteem after succeeding with the therapy goals. As Paul's relationships with his father and brothers improved, mainly due to the changes on his part, he reported feeling less isolated and an important part of his family. His loving relationship and emotional intimacy with his girlfriend and subsequent marriage helped him feel more like other men and not "a freak" as he once put it. He said, "I never imagined the joy of sex I experience with my wife who gives herself to me with her full consent, maturity, and loving conversation; this was never available to me when I used cows to masturbate myself." He felt God had forgiven him and he had forgiven others and himself for violating "God's innocent creatures" (cows).

I told Paul that I was pleased with the progress he had made given the tendency of people with paraphilia to relapse. I stressed that it was important for him to continue practicing the things he had learned from Fr. John and me. Because he believed God had forgiven him and he had asked the forgiveness of all the animals he had violated, he did not feel the need to burden his wife with any of his past issues. Out of a list of many scriptures Paul carried around with him on two pages, I list the three he read to me to justify his decision about this issue: (1) "If we confess our sins, he is faithful and just to forgive us our sins, 
and to cleanse us from all unrighteousness"- 1 John 1:9; (2) "And their sins and iniquities will I remember no more" - Hebrews 10:17; and (3) "Therefore if any man be in Christ, he is a new creature: old things are passed away; behold, all things are become new" - 2 Corinthians 5:17 [21].

During all follow-up sessions, Paul denied any relapse when he visited his family farm with his wife on special occasions. He said he will continue making short visits only on special occasions. Instead he invited his parents, brothers and their families to visit him and his wife in the city at different times.

\section{Discussion}

The case of Paul shows that recovering from the ego-dystonic zoophilia is a process that requires considerable time, effort, and commitment. By acknowledging that one has a serious problem and it is causing a considerable personal discomfort, one can go on a journey of extinguishing the behavior and preventing the relapse with the help of a caring, open minded and skilled psychotherapist, a stance also supported by Miletski [8]. Paul's case of zoophilia displayed several causative factors reported in the literature, for example, living on the farm with free access to cows, isolated from others, introduced and reinforced by the cousin to SCA (a form of sex abuse), low social activity, fear of intimacy with women, and perceived rejection and emotional abuse by parents and brothers. Choice of SCA in this case was situational, mechanical, and a substitute for a lack of peer relationships. This picture coincides with the description of persons with zoophilia by the "traditional view of zoophilia" [4,5,11]. Paul's unexpected birth, lack of parental enthusiasm upon his arrival, and age difference between Paul and his brothers set a stage for Paul to feel emotionally rejected. His isolated living left Paul to invent his own personal world of entertainment which included his fantasies, singing, and sexual play with the cows, all which has been reported by other researchers as the antecedent factors $[1,8,11]$. He also felt inept in making friends and dating girls during his adolescent years, thus the sexual energies of a maturing young man got mixed up with cows under the influence of his cousin. Paul did not fit the classic case of low intellectual ability as reported by some researchers $[4,8]$. In fact, he was of above average intelligence which I consider was a strong factor for his good prognosis. The association of low intellectual ability and zoophilia was also questioned by some other researchers [13]. It is my contention that in order to have a chronic experience of zoophilia, one has to be of average or above average intelligence to invent ways to remain hidden from the public scrutiny and legal repercussions.

Paul's choice of SCA was a result of traditional causative factors and not a preference for SCA than the human sexual experience as has been indicated for some by the "modern view of zoophilia" $[1,8,12,13]$. Paul understood a lot about zoophilia through his readings which facilitated his therapy. I believe in educating the clients and making them understand the dynamics and etiology of their pathology, then enlisting their collaboration in combating the problem. In this case, Paul also educated me on the subject by sharing sources and asking questions for which I had to look up the answers. Also, Paul's case is a great example of including the most overlooked and yet an important dimension of human functioning, our spirituality. Including this aspect within the multimodality profile of Paul created a holistic treatment plan.

Being a legal offense in many states and countries, zoophilia is an important community health concern. To understand this phenomenon, it is critical to see the multimodal picture. Because there is a great paucity of research with this taboo subject, there is no clear answer to the question of etiology. Different cases display different sets of variables. Thus, at the present time, psychotherapists would need to look at each case with fresh eyes. In my opinion, multimodal approach is the best way to treat a case of zoophilia. Further, two key factors for success are ego-dystonic nature of the problem and client's motivation to change. Mileteski [8] also considered client's motivation as an important factor for change. Miletreski in her study concluded that most of the "true zoophilia" cases are not treatable, however, if a person is highly motivated, his/her acting out can be stopped. She further stated that the attraction and the desire do not vanish. I have two problems with her conclusion. I do not like the term "true zoophilia" and I do not believe that the problem is untreatable. I do agree with her that the client needs to be highly motivated to change. I also agree with Miletreski about the importance of the psychotherapists to be well informed, aware of their own sexual attitudes and biases, and accepting of the clients who are living a life of "secrecy and fear."

There are a few important issues connected to zoophilia which came to light during my work with Paul and review of the limited literature on the subject. Paul stated that he used cows as objects of masturbation "who did not have any say." Our civilized society accepts that animals should be treated humanely and cared for properly. But the laws in U.S. and elsewhere are varied and unclear about the definition of animal cruelty (abuse), zoophilia/bestiality, and penalties for violation. Scholars from different disciplines have argued about the confusion, psychopathology of zoophilia, lack of research, lack of attention to the animal rights, justification for the behavior, and occult nature of this phenomenon $[1,3,8,10,13]$. The staff editor of Hastings Women's Law Journal, Maria Turcios raised some good points in her article [2] about the downplaying of the seriousness of zoophilia. She stated that some United States do not provide needed steps to deal with the sexual assaults of unconsenting animals; sodomization wounds them. Peretti and Rowan [11] reported in their study of 51 chronic zoophiles that both men and women considered their behavior as a form of masturbation. Thus, the individuals who have SCA are using unconsenting animals as masturbatory objects. Beetz reported in her study of 113 men and 3 women involved in SCA that three-quarters of them had a strong emotional attachment with their animals [1]. This argument has been used to justify the practice of zoophilia by giving it an appearance of love similar to between two humans. But it is clearly not an even exchange. Peretti and Rowan [1] explain the reason for occurrence of this phenomenon: "It is not unusual for persons engaging in sexual activities to develop feelings of affection toward the sexual object" [1, p.130]. SCA is an illegal act in most of the world and many arguments that hold true against sexual contact with children are also applicable to sexual contact with animals. At any rate, it behooves us to consider the following questions.

1. As has been indicated by some, if SCA is harmless/normal, then would it be acceptable if one's neighbor or friend has sex with one's dog, horse, cat, etc?

2. Just because there is not much research about the subject, does that make zoophilia an unimportant community health issue?

3. Is sodomizing an animal a lesser abuse than using a dog in a dog fight?

4. Since an animal cannot give consent for sex, are there any similarities between child sex abuse and SCA? And should SCA be dealt with the similar regulations as child sex abuse? 


\section{Conclusions}

It has been an interesting pursuit researching and writing about one of the most stigmatized, complex, and least researched paraphilias. There are several aspects of zoophilia/bestiality which have not been addressed in this report due to the space limitation and lack of information. I focused mainly on the dynamics, etiology, and treatments of ego-dystonic zoophilia. To my knowledge, the present article is the first one to present a comprehensive treatment plan for zoophilia which resulted in successful outcomes. Contrary to some recent studies, the current case study supported the earlier research conclusions. Also, Paul's motivation to turn his life around was considered the major factor for the successful outcome of the treatment. Multimodal therapy was considered to be the most appropriate therapy with ego-dystonic zoophilia. Based on the current case study and review of the other studies, following factors are identified as good prognosis predictors for zoophilia for therapy.

1. When an individual is not in love with the animal, not having sex exclusively with one animal, and not considering the animal as a sex partner or spouse.

2. Ego-dystonic nature of the experience.

3. High motivation to change.

4. Use of SCA as a form of masturbation and not a preference over sexual contact with humans.

5. Lack of other avenues of sexual expression.

\section{References}

1. Beetz AM (2004) Bestiality/zoophilia: a scarcely investigated phenomenon between crime, paraphilia, and love. Journal of Forensic Psychology Practice 4: 1-36.

2. Turcios M (2014) Bestiality laws: our dirty little secret. Hastings Women's Law Journal Available at http://hastingswomenslj.org/journal/2014/2/20/ e3y5p9h4xformoldf658mebzcse7va

3. Holoyda B, Newman W (2014) Zoophilia and the law: legal responses to a rare paraphilia. J Am Acad Psychiatry Law 42: 412-420. [Crossref]

4. Kinsey AC, Pomeroy WB, Martin CE (1948) Sexual behavior in the human male. Philadelphia: Saunders Company.

5. Hunt M (1974) Sexual behavior in the 1970s. Chicago, IL: Playboy Press.
6. Kinsey AC, Pomeroy WB, Martin CE, Gebhart PH (1948) Sexual behavior in the human female. Philadelphia: Saunders Company.

7. Gebhard PH, Gagnon JH, Pomeroy WB, Christenson CV (1965) Sex offenders: an analysis of types. New York: Harper Row.

8. Miletski H (2015) Zoophilia - Implications for Therapy. Journal of Sex Education and Therapy 26: 85-86.

9. Alvarez WA, Freinhar JP (1991) A prevalence study of bestiality (zoophilia) in psych iatric inpatients, medical in-patients, and psychiatric staff. Int J Psychosom 38: 45-47. [Crossref]

10. Ranger R, Fedoroff P (2014) Commentary: Zoophilia and the law. J Am Acad Psychiatry Law 42: 421-426. [Crossref]

11. Peretti PO, Rowan M (1982) Variables associated with male and female chronic zoophilia. Social Behavior and Personality 10: 83-8.

12. Donofrio R (1996) Human/animal sexual contact: a descriptive exploratory study Doctoral Dissertation. San Francisco, CA: The Institute of Advanced Study of Human Sexuality.

13. Earls CM, Lalumière ML (2009) A case study of preferential bestiality. Arch Sex Behav 38: 605-609. [Crossref]

14. Burgemeester A (2014) What is the Difference Between Ego Syntonic and Ego Dystonic? Psychologized. Available at http://psychologized.org/what-is-the-differencebetween-ego-syntonic-and-ego-dystonic/

15. American Psychiatric Association (2013). Diagnostic and statistical manual of mental disorders, Fifth edition. Washington DC: American Psychiatric Association.

16. Lazarus AA (1989) The practice of multimodal therapy. Baltimore: Johns Hopkins University Press.

17. Alcoholics Anonymous 12 Steps. Available at https://www.addictioncenter.com/ treatment/12-step-programs/

18. Washington State Department of Health (2016) Available at

19. http://www.doh.wa.gov/YouandYourFamily/I1lnessandDisease/ AnimalTransmittedDiseases

20. Zequi SC, Guimarães GC, da Fonseca FP, Ferreira U, de Matheus WE, et al. (2012) Sex with animals (SWA): behavioral characteristics and possible association with penile cancer. A multicenter study. J Sex Med 9: 1860-7. [Crossref]

21. Health 24 (2015) Bestiality is much, much more common than you think. Available at http://www.health24.com/Sex/Sexual-diversity/Bestiality-is-much-much-morecommon-than-you-think-20150218

22. Bible Gateway, King James Version (KJV). Available at https://www.biblegateway. $\mathrm{com} /$ passage/?search $=$ Philippians $+4 \% 3 \mathrm{~A} 13$ \&version $=\mathrm{KJV}$

Copyright: (C2016 Singg S. This is an open-access article distributed under the terms of the Creative Commons Attribution License, which permits unrestricted use, distribution, and reproduction in any medium, provided the original author and source are credited. 